\title{
Effect of alprostadil on erythrocyte deformability in ischemia reperfusion injury
}

\author{
Kara $\mathrm{H}^{1}$, Ozer $\mathrm{A}^{2}$, Arpaci $\mathrm{H}^{3}$, Demirtas $\mathrm{H}^{2}$, Comu $\mathrm{FM}^{4}$, Oktar $\mathrm{GL}^{2}$, Erer $\mathrm{D}^{2}$, Kucuk $\mathrm{A}^{5}$, Arslan $\mathrm{M}^{6}$ \\ Department of of Pharmacology, Yildirim Beyazit University Medical Faculty, Ankara, Turkey. \\ marslan36@yahoo.com
}

\begin{abstract}
BACKGROUND: Ischemia reperfusion injury (I/R) in lower extremity is a frequent and important clinical phenomenon. Protective effect of alprostadil on local and distant organ injury due to I/R has been well-documented but its effect on erythrocyte deformability needs further investigation. Our aim was to investigate the effect of alprostadil on erythrocyte deformability in infrarenal aorta of rats undergoing I/R.

MATERIALS AND METHODS: Our study was conducted with 18 Wistar albino rats. Rats were divided into 3 groups; randomized control group (group $\mathrm{C} ; \mathrm{n}=6$ ), I/R group without alprostadil (group I/R; $n=6$ ) and I/R group with alprostadil 20 mcg. $\mathrm{kg}^{-1}$, intraperitoneal (group I/R-A; $n=6$ ). Packs of erythrocytes were prepared from heparinized blood samples and deformability measurements were done.

RESULTS: Comparisons of the control and I/R-A groups revealed similar results $(p=0.240)$. The values of the IR group were significantly higher than those of the control and IR-A groups ( $p=0.009, p=0.026$, respectively). CONCLUSION: In our study, we detected unfavourable effects of I/R on erythrocyte deformability, which may lead to disturbance in blood flow and hence tissue perfusion in infrarenal rat aorta. We also found that alprostadil had beneficial effects by reversing undesirable effects of I/R (Fig. 1, Ref. 22). Text in PDF www.elis.sk. KEY WORDS: erythrocyte deformability, ischemia reperfusion, alprostadil, rat.
\end{abstract}

\section{Introduction}

Ischemia reperfusion injury (I/R) in lower extremity is a frequent and important clinical phenomenon. Reperfusion period following an ischemic insult may paradoxically cause increased rates of mortality and morbidity due to systemic complications. Local oedema and muscle tissue necrosis are likely to be followed by systemic inflammatory response syndrome and multiple organ failure (kidney, respiratory and circulatory system etc.) as the reperfusion advances (1-3).

Swelling of cells, degeneration of cell skeleton structure and loss of selective membrane permeability are the characteristic features of reperfusion injury. These changes all end up with tissue oedema and decreased capillary blood flow (4).

The well known vasodilatory effect of prostaglandins is attributed to the inhibition of the vasoconstrictional effect of leukotriene

${ }^{1}$ Department of of Pharmacology, Yildirim Beyazit University Medical Faculty, Ankara, Turkey, ${ }^{2}$ Department of Cardiovascular Surgery, Gazi University Medical Faculty, Ankara, Turkey, ${ }^{3}$ Department of Oral and Maxillofacial Surgery, Ankara University Faculty of Dentistry (Anaesthesiology Reanimation specialist) Besevler, Ankara, Turkey, ${ }^{4}$ Department of Physiology, Kirikkale University Medical Faculty, Kirikkale, Turkey, ${ }^{5}$ Department of Physiology, Dumlupinar University Medical Faculty, Kütahya, Turkey, and ${ }^{6}$ Department of Anaesthesiology and Reanimation, Gazi University Medical Faculty, Ankara, Turkey

Address for correspondence: M. Arslan, Dr, Gazi University Medical Faculty, Department of Anesthesiology and Reanimation, 06510 Ankara, Turkey.

Phone: +90.3122026739
$\mathrm{D}(4,5) . \mathrm{PGE}_{1}$ inhibits also platelet aggregation, is cytoprotective, enhances fibrinolytic activity, downregulates ICAM-1, VCAM-1, and E-selectin (6), upregulates thrombomodulin (7), and inhibits smooth muscle cells proliferatio (8).

Prostaglandin $_{\mathrm{E} 1}\left(\mathrm{PGE}_{1}\right)$ has protective effects against acute and chronic ischemia in various organs (9-14).

Benefits of alprostadil to prevent local and distal tissue injury due to $\mathrm{I} / \mathrm{R}$ has been well-documented so far. However, little is known about its protective effect on erythrocyte deformability after I/R injury. Our study aims to investigate the effect of alprostadil on lower extremity muscle ischemia and subsequent I/R injury, which may happen frequently after the tourniquet method.

\section{Materials and methods}

\section{Animals and experimental protocol}

This study was conducted in the Physiology Laboratory of Kirikkale University upon the consent of Experimental Animals Ethics Committee of Gazi University. All of the procedures were performed according to accepted standards of Guide for the Care and Use of Laboratory Animals.

In our study, 18 Wistar Albino rats weighing between 200 and $250 \mathrm{~g}$, raised under the same environmental conditions, were used. The rats were kept under $20-21^{\circ} \mathrm{C}$ at cycles of 12 -hour daylight and 12-hour darkness and had free access to food until 2 hours before the anesthesia procedure. The animals were randomly separated into four groups, each containing 6 rats. Midline laparatomy was done under ketamine anesthesia. 
509-511

\section{Control group}

Midline laparotomy was done alone without any additional surgical intervention. Blood sample was collected after 2 hours of follow-up and animals were sacrificed eventually.

\section{I/R group}

Midline laparotomy was done similiarly. Infrarenal segment of the aorta was clamped for 2 hours. After removing the clamp, reperfusion was established for another 2 hours. Finally, rats were sacrificed after collecting blood samples from their abdominal aorta.

\section{I/R group with alprostadil}

Similar steps were followed, but in addition to the procedure mentioned above, alprostadil was given $\left(20 \mathrm{mcg} \cdot \mathrm{kg}^{-1}\right)$ intraperitoneally starting simultaneously with the reperfusion period. Rats were sacrificed at the end of reperfusion period, which lasted 2 hours after collecting blood samples.

All the rats were given ketamine $100 \mathrm{mg} \cdot \mathrm{kg}^{-1}$ intraperitoneally and intraabdominal blood samples were obtained. Heparinized total blood samples were used to prepare erythrocyte packs. Deformability measurements were done using erythrocyte suspensions with $5 \%$ hematocrit in phosphate buffered saline (PBS) buffer.

\section{Deformability measurements}

Blood samples were taken very carefully and measurement process was done as fast as possible to avoid hemolysis. Collected blood was centrifuged at $1000 \mathrm{rpm}$ for ten minutes. Serum and buffy coat on erythrocytes were removed. Isotonic PBS buffer was added to collapsing erythrocytes and this mixture was centrifuged at $1000 \mathrm{rpm}$ for ten minutes. Liquid on the upper surface was removed. Finally, pure red cell packs were obtained from the washing process, which was repeated three times. Erythrocyte packs were mixed with PBS buffer to generate a suspension with the value of $5 \% \mathrm{Htc}$. Those erythrocyte suspensions were used for the measurement of deformability. Collection and deformability measurements of erythrocytes were done at $22{ }^{\circ} \mathrm{C}$.

The constant-current filtrometer system was used for measurement of erythrocyte deformability. Samples to be measured were prepared as $10 \mathrm{ml}$ of erythrocytes suspension and PBS buffer. The flow rate was held constant at $1.5 \mathrm{ml} / \mathrm{min}$ with an infusion pump. A $28 \mathrm{~mm}$ nucleoporin polycabonate filter with a $5 \mu \mathrm{m}$ pore diameter was preferred. Pressure changes while the erythrocytes were passing through the filter, were detected by the pressure transducer and the data was transferred to computer with the help of MP 30 data equation systems (Biopac Systems Inc, Commat, USA). The necessary calculations were performed with related computer programs by measuring the pressure changes at various times. Pressure calibration of the system was performed each time before measuring the samples. Firstly buffer (PT) and then erythrocytes $(\mathrm{PE})$ passed through the filtration system and the changes in pressure were measured. The relative refractory period value (Rrel) was calculated by relating the pressure value of erythrocyte suspension to pressure value of buffer. Increase in Rrel as the deformability index was interpreted as adversely affecting the ability of erythrocyte deformability $(7,8)$.

\section{Statistical analysis}

The statistical analyses were performed with the SPSS 17.0 software program and $p<0.05$ was considered statistically significant. The findings were expressed as the mean \pm standard deviation. The data were evaluated with the Kruskal-Wallis variance analysis. The variables with significance were evaluated with Bonferroni corrected Mann-Whitney U test.

\section{Results}

The results of the study indicated that IR significantly increased the relative resistance, a marker of erythrocyte deformability when compared to control and IR-A groups $(\mathrm{p}<0.05)$ (Fig. 1).

There were significant differences between the groups according to the comparisons with Kruskal-Wallis test $(p=0.012)$. The results obtained after corrections with Bonferroni test were as follows: comparisons of the control and IR-A groups revealed similar results $(p=0.240)$. The values of the IR group were significantly higher than those of the control and IR-A groups ( $\mathrm{p}=$ $0.009, \mathrm{p}=0.026$, respectively).

\section{Discussion}

Prostaglandin $\mathrm{E}_{1}\left(\mathrm{PGE}_{1}\right.$; Alprostadil, Minprog ${ }^{\circledR}$, Pharmacia \& Upjohn, Erlangen, Germany) is chemically more stable and its clinical use is more frequent compared to $\mathrm{PGE}_{2}$. $\mathrm{PGE}_{1}$ has cytoprotective and vasodilator effects, reduces oxygen consumption and superoxide anion production in ischemia-reperfusion injury (15).

Numerous trials and experimental studies have shown that $\mathrm{PGE}_{1}$ protected and reduced ischemia-reperfusion injury in various organs (10-14). On the other hand, Gabriel et al (16) reported that $\mathrm{PGE}_{1}$ had a negative effect on ischemia-reperfusion injury during AAA surgery.

PGE $_{1}$ administration will not prevent the showering of emboli, but it will improve microcirculation of the lower extremities.

For migration of oxygen and vital molecules to the final organ capillaries and clearance of metabolic wastes, erythrocytes must be able to extend and curve and have the capability to move in these areas. This capacity, termed as "deformability" becomes more important in microcirculation. Altered erythrocyte deformability not

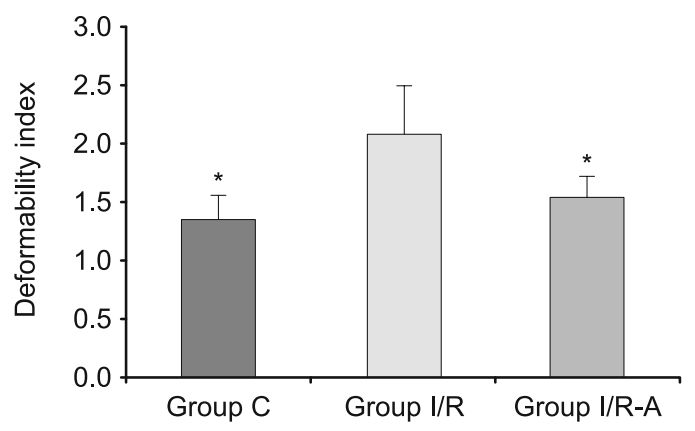

Fig. 1. Erythrocyte deformability index values of the groups. Each bar represents the mean \pm SD. ${ }^{*} \mathbf{p}<0.05$ compared to the Group I/R. 
only changes the oxygen delivery capacity of the erythrocytes but also the survival of the circulating erythrocytes (17-19).

Yamaguchi et al (20) showed conclusively that CPB has a detrimental effect on red cell deformability and that this effect is accentuated by prolongation of $\mathrm{CPB}$ time. $\mathrm{PGE}_{1}$ lessened the decrease in red cell deformability during $\mathrm{CPB}$ and was shown to be very effective for the prevention of hemolysis.

Henley et al (21) used PGE 1 prophylactically in 160 adult orthotopic liver transplant recipients and found no statistically significant difference in the incidence and the results of PNF between the $\mathrm{PGE}_{1}$ and placebo groups in a double-blind placebo-controlled trial. On the other hand, $\mathrm{PGE}_{1}$ administration was shown to have positive immunological, hemodynamic, hematological effects and to shorten mean duration of hospitalization (22).

All these data and our findings indicate that erythrocyte deformability is impaired in rats subjected to I/R and this impairment leads to disturbance of microvascular perfusion and related problems. So, we think that the measurement of erythrocyte deformability can be useful as a parameter in cases of I/R. We also observed a beneficial effect of alprostadil infusion on maintaining erythrocyte deformability during periods of $\mathrm{I} / \mathrm{R}$ but we still think these promising results should further be supported by more detailed studies with larger volumes.

\section{References}

1. Duru S, Koca U, Oztekin S et al. Antithrombin III pretreatment reduces neutrophil recruitment into the lung and skeletal muscle tissues in the rat model of bilateral lower limb and reperfusion: A pilot study. Acta Anaesthesiol Scand 2005; 49: 1142-1148.

2. Turchanyi B, Toth B, Racz I et al. Ischemia reperfusion injury of skeletal muscle after selective deafferentation. Physiol Res 2005; 54: 25-32.

3. Lin B, Ginsberg M, Busto R, Li L. Hyperglycemia triggers massive neutrophil deposition in brain following transient ischemia in rats. Neurosci Lett 2000; 278: 1-4.

4. Homer-Vanniasinkam S, Crinnion JN, Gough MJ. Post-ischaemic organ dysfunction: a review. Eur J Vasc Endovasc Surg 1997; 14: 195-203.

5. Wohlrab J, Fischer M, Marsch WC. Current diagnosis of Sneddon syndrome. Dtsch Med Wschr 2001; 126: 725-728.

6. Magy N, Algros MP, Racadot E, Gil H, Kantelip B, Dupond JL. Liveoid vasculopathy with combined thrombophilia: efficacy of iloprost. Rev Med Interne 2002; 23: 554-557.

7. Tsutsui K, Shirasaki F, Takata M, Takehara K. Successful treatment of livedo vasculitis with beraprost sodium: a possible mechanism of thrombomodulin upregulation. Dermatology 1996; 192: 120-124.

8. Wohlrab J, Fischer M, Marsch WC. Current therapy of Sneddon's syndrome. Dtsch Med Wschr 2001; 126: 758-760.
9. Mofarrah F, Aberer W, Aberer E. Treatment of livedoid vasculopathy with alprostadil (PGE-1): case report and review of published literature. J Eur Acad Dermatol Venereol 2013; 27 (2): e252-254.

10. Feld S, Li G, Wu A, Felli P, Amirian J, Vaughn WK et al. Reduction of canine infarct size by bolus intravenous administration of liposomal prostaglandin E1: comparison with control, placebo liposomes, and continuous intravenous infusion of prostaglandin E1. Am Heart J 1996; 132 (4): 747-757.

11. Huk I, Brovkovych V, Nanobashvili J, Neumayer C, Polterauer P, Prager M et al. Prostaglandin E1 reduces ischemia/reperfusion injury by normalizing nitric oxide and superoxide release. Shock 2000; 14 (2): 234-242.

12. dePerrot M, Fischer S, Liu M, Jin R, Bai XH, Waddell TK et al. Prostaglandin E1 protects lung transplants from ischemia- reperfusion injury: a shift from pro- to anti-inflammatory cytokines. Transplantation 2001; 72 (9): 1505-1512.

13. Sketch MH Jr, Whelton A, Schollmayer E, Koch JA, Bernink PJ, Woltering F et al. Prostaglandin E1 Study Group. Prevention of contrast media-induced renal dysfunction with prostaglandin E1 a randomized, double-blind, placebo-controlled study. Am J Ther 2001; 8 (3): 155-162.

14. Krueger U, Scholz H, Heise M, Adeberg P, Petzold M, Zanow J et al. Effect of intravenous iloprost and alprostadil (PGE1) on peripheral resistance during femoro-distal reconstructions. Int Angiol 2000; 19 (4): $358-365$.

15. Robert C, Marian A, Ross C et al. Liver transplantation and surgery. Ann Surg 1996; 1: 23-36.

16. Gabriel A, Werba A, Mares P, Grubhofer G, Hrska F, Griesmacher A et al. Influence of prostaglandin E1 on tissue ischemia during surgical repair of the abdominal aorta. J Cardiothorac Vasc Anesth 1996; 10 (2): 201-206.

17. Zinchuk VV. Erythrocyte deformability: physiological aspects. Usp Fiziol Nauk 2001; 32 (3): 66-78.

18. Kuypers FA. Red cell membrane damage. J Heart Valve Dis 1998; 7: 387-395.

19. Sivilotti ML. Oxidant stres and haemolysis of the human erythrocyte. Toxicol Rev 2004; 23: 169-188.

20. Yamaguchi H, Shimizu T, Akutsu H, Kawachi K, Osada K, Fujikawa $\mathbf{T}$ et al. Hemolysis and red cell deformability during cardiopulmonary bypass - the effect of prostaglandin E1 for prevention of hemolysis. Nihon Kyobu Geka Gakkai Zasshi 1990; 38: 625-629.

21. Henley KS, Lucey MR, Normolle DP et al. A double-blind randomized placebo- controlled trial of prostaglandin E1 in liver transplantation. Hepatology 1995; 21: 366-372.

22. Bigelow DJ, Thomas DD. Rotational dynamics of lipid and the CaATPase in sarcoplasmic reticulum. The moleküler basis of activation by diethylether. J Biol Chem 1997; 262: 13449-13456.

Received October 6, 2014. Accepted February 12, 2015. 